\title{
Associative symmetry: III. Complex maze learning in humans
}

\author{
LEONARD BROSGOLE and THERESA M. WESSNER \\ St. John's University, Jamaica, New York 11439
}

\begin{abstract}
Two groups of subjects ( 1 and 2 ) were required to learn a 10-choice pencil maze. A backward trial was interpolated every sixth run, with Group 1 going from goal to start on the same maze and Group 2 making the return trip on a different maze. Group 1 learned the backward task significantly faster than Group 2, indicating that associative symmetry occurred during forward learning.
\end{abstract}

An earlier series of studies (Brosgole \& Lepak, 1976; Brosgole, Neylon, \& Ulatowski, 1976) found evidence for backward learning when animals were required to respond to position in a $\mathrm{Y}$ maze. Essentially, gerbils were trained to turn to the right or left to escape from heat that was being applied to the paws. For every five forward trials there was an interpolated back run, where the animal was placed either in the positive or negative goal and required to return back to the startbox. The results strongly indicated that backward place learning occurred during frontward training. Two problems emerged, however. First, backward learning was invariably and inexplicably superior to forward learning. These unorthodox asymmetry findings may have been due to an artifact, namely, the relative massing of frontward compared to backward practice. Second, although there were attempts to control for the use of chemical cues in accomplishing backward learning, olfaction could not be completely ruled out. The present endeavor represents a logical extension of the previous animal studies. It dealt with the problem of associative symmetry in complex maze learning in humans.

Two groups of subjects were required to learn a 10choice pencil maze (presumably devoid of olfactory cues) while blindfolded. A back run, from goal to start, was interpolated on every sixth trial. While one group (Group 1) performed the back trial on the same maze, the other (Group 2) made the return run on a different 10-choice maze. It was reasoned that Group 1 should have learned the backward task significantly faster than Group 2, if forward training resulted in associative symmetry. However, no difference between the groups could be expected if there was a failure of backward association.

\section{METHOD}

\section{Subjects}

Forty eight males and 48 females participated in this

The authors extend their appreciation to Ann Neylon for her most helpful comments. study. Ranging in age from 18 to 25 years, their median age was 21.0 years. They were all university students who were naive as to the purpose of the experiment.

\section{Apparatus}

Two Lafayette Instrument 10-choice pencil mazes were used. Standard $8 \frac{1}{2} \times 11$ in. paper was placed underneath the maze on each trial, thereby permitting the number of errors to be recorded.

\section{Procedure}

The subject was told that he would be required to learn to correctly trace a maze with a pencil from start to finish as well as finish to start while blindfolded. A trial consisted of placing a blank sheet of paper under the maze, guiding the subject's hand to the starting position, and permitting him to trace freely until reaching the finishing point. The hand was then removed from the maze and a fresh piece of paper was placed underneath for the next trial.

There were five forward to one back trials, with the back run interpolated on every sixth trial. Two mazes (A and B) were used. The mazes were similar in the directional relationship of start to goal, but differed in terms of their pathways. While one group of 48 subjects (Group 1) made the return trip on the same maze, the other (Group 2) traced backward on the other maze. (In the instructions, Group 1 was informed that they would be required to learn the same maze in two directions and Group 2 was told that they would have to learn two different mazes.) Half of each group received forward training on Maze $A$, and the other half on the $B$ maze. In addition, forward training consisted of tracing either away from the body or toward the body. Therefore, half of the subjects traced away from the body for five trials followed by one trial of coming back toward the body. The opposite applied to the remaining subjects. (The initial intent of the study was to compare forward to backward learning in Group 1 . At that point, it was important to counterbalance the direction of tracing. However, the subsequent addition of Group 2 rendered such a control totally unnecessary.) Thus, the two mazes and direction of tracing were completely counterbalanced over subjects. An equal number of males and females were assigned to each counterbalanced treatment.

Training continued until the subject met the criterion of one errorless forward and backward run. Trials to criterion and errors were recorded.

\section{RESULTS AND DISCUSSION}

Since the forward training means for the different mazes and directions of tracing were similar, the data were collapsed into two main groups, Group 1 running 
back on the same maze and Group 2 returning on a different maze. In addition, a direct comparison of forward to backward learning did not seem appropriate, because the forward training was massed, while the back trials were distributed. Therefore, Groups 1 and 2 were evaluated in terms of forward leaming and then compared on the basis of backward performance.

Group 1 mastered the forward task in a mean of 20.21 trials, committing 66.25 errors. Group 2 required 19.14 trials to reach criterion, while making 70.56 errors. Because the two groups did not differ significantly in trials $(T=.464)$ as well as errors $(T=.440)$, they were then compared in terms of backward learning.

Group 1 reached the backward criterion in 9.42 trials, making 27.58 errors. This represented a savings of $53 \%$ in trials and $58 \%$ in errors with respect to forward learning. Group 2 needed 15.56 trials to learn the back run and made 53.59 errors. This was a savings of $19 \%$ in trials and $24 \%$ in errors. The two groups differed significantly, both in back trials $(T=4.676$, $\mathrm{p}<.01)$ and errors $(\mathrm{T}=4.617, \mathrm{p}<.01)$. Clearly, there was positive transfer from the forward to the backward task in both groups. In part, this transfer may have been due to a practice effect as well as the novelty and distribution of the back trials. However, the significance of the difference between the two groups indicated that Group 1 benefited more from forward training than did Group 2. It was reasoned that the development of symmetrical learning during the forward trials could be the only basis for the difference in their performance levels, since both groups benefited equally from the distribution of backward practice.

It may be recalled that the subject was explicitly instructed to learn the maze in both directions. These instructions, along with the interpolation of a back run on every sixth trial, were aimed at precluding the buildup of a forward learning set. It can be argued that such a paradigm inadvertently had the net effect of directing the subject to silently memorize the turns in a backward fashion during the front trials, resulting in the formation of two unidirectional connections, one from start to finish and the other from finish to start. This would have facilitated the backward performance of Group 1, and negatively affected Group 2. As a check against this possibility, an interview followed each testing session. A great majority of the subjects felt that the back trials were interpolated merely to confuse or interfere with forward performance. They indicated unanimously that forward learning was so difficult that it was impossible to undertake simultaneous backward rehearsal. In fact, there was a concerted mental effort to block out the interpolated back runs until forward learning was well under control. Because there was no intent to learn the return trips until the very end, the subjects expressed surprise at having achieved backward criterion so quickly. The data support the subjects' denial of backward practice in the front runs. It made sense for the subjects in Group 1 only to attempt to undertake such practice. Thus, Group 1 would have imposed two tasks upon itself in the front runs, compared to only one task for the people in Group 2. That should have resulted in a significant difference between the groups in forward trials and errors. The fact that the groups did not differ in forward training seems to rule out the possibility of the silent rehearsal of the backward turns. Thus, it would appear that associative symmetry occurs in learning a complex maze.

\section{REFERENCES}

Brosgole, L.. \& Lepak, C. Associative symmetry: I. Position learning in the gerbil. Bulletin of the Psychonomic Society, 1976, 7, 99-102.

Brosgole, L., Nyelon, A., \& Ulatowski, P. Associative symmetry: II. Further studies of position learning in the gerbil. Bulletin of the Psychonomic Society, 1976, in press.

(Received for publication October 26. 1975.) 